\title{
Basic Evaluation of Gelatinous Fat to Improve Properties of Nursing Care Food
}

\author{
Junya Sano ${ }^{1,2 *}$, Ryuji Noda ${ }^{1}$, Shinji Watanabe ${ }^{1}$, Toshiaki Aoyama ${ }^{1}$, Yukinori Sato ${ }^{2}$, \\ Jun Kayashita ${ }^{2}$ and Norio Muto ${ }^{2}$ \\ ${ }^{1}$ The Nisshin Oillio Group, Ltd., 1-23-1 Shinkawa, Chuo-ku, Tokyo 104-8285, Japan \\ ${ }^{2}$ Graduate School of Comprehensive Scientific Research, Prefectural University of Hiroshima, 1-1-71 Ujina-Higashi, Minami-ku, Hiroshima \\ 734-8558, Japan
}

\begin{abstract}
Nursing care food, made smooth and soft by adding a substantial amount of water, has been provided to elderly people who exhibit a decline in chewing and swallowing function. However, this is associated with problems such as an increase in the volume of meals and a decrease in the nutritional value per unit weight, causing malnutrition. To resolve these issues, we aimed to develop gelatinous fat suitable for processing nursing care food. We compared several types of oil and fat including this gelatinous fat using rheology measurement and sensory evaluation. In the measurement of fat alone using a dynamic viscoelastometer, the gelatinous fat had the highest values of storage elastic modulus $\left(G^{\prime}\right)$ and loss elastic modulus $(G$ ') at the predetermined ranges of temperature and frequency. In the measurement of fat mixed with food using a creep meter, the gelatinous fat showed a significantly lower level of firmness and a higher level of cohesiveness than other types of fat. In the sensory evaluation, food processed with gelatinous fat was evaluated to be better than food processed with no addition or the addition of another type of fat in terms of softness, smoothness, low feeling of residual food, and palatability. These results suggest that the newly developed gelatinous fat is most suitable for nursing care food processing among the types of fat examined. It is expected that nursing care food processed with gelatinous fat can facilitate the consumption of food with high energy and reduce the risk of malnutrition in the elderly.
\end{abstract}

Key words: nursing care food, minced food, protein energy malnutrition (PEM), gelatinous fat

\section{INTRODUCTION}

According to a government survey in 2013, the Japanese elderly population aged 65 or over was estimated to be approximately 32 million and its proportion exceeded $25 \%$ for the first time. The number of elderly people requiring nursing care for daily living was over 5.6 million, which will tend to increase in the future. Elderly people requiring nursing care have various problems in their lives. In particular, they face problems with meals, which are mainly related to reductions of masticatory and swallowing functions and nutritional intake.

The masticatory and swallowing functions of the elderly become more impaired as the level of nursing care increas$\mathrm{es}^{1)}$. Therefore, the nursing care food that is provided to the elderly requiring nursing care must be adjusted so that it is easy to swallow. The most common form of nursing care food is minced food, which has been utilized in more than $90 \%$ of nursing care facilities in Japan ${ }^{2,3)}$. Minced food is chopped finely with a kitchen knife or a food processor so it can be easily eaten by elderly people who have declined masticatory function ${ }^{4}$. In general, food is mixed with saliva and forms a soft bolus after mastication, which facilitates swallowing ${ }^{5}$. Therefore, minced food, which is just finely chopped, is unlikely to form a bolus in elderly people, resulting in increased difficulty in the aspiration of food $^{6,7)}$.

Prolonged malnutrition is known to cause protein energy malnutrition (PEM). PEM is likely to occur as the level of nursing care increases ${ }^{8}$. PEM impairs the activities of daily living (ADL) and the quality of life (QOL), together with a decrease of immunity and increases of disease morbidity and complication rates. Elderly people with such underlying conditions have an increased risk of pneumonia if they aspirate food ${ }^{9-11}$. PEM is caused by factors such as age-related impairments in masticatory and digestive-absorptive functions, anorexia, and a decrease of food intake due to

\footnotetext{
*Correspondence to: Junya Sano, The Nisshin Oillio Group, Ltd., 1-23-1 Shinkawa, Chuo-ku, Tokyo 104-8285, Japan

E-mail: j-sano@nisshin-oillio.com

Accepted February 27, 2015 (received for review December 9, 2014)

Journal of Oleo Science ISSN 1345-8957 print / ISSN 1347-3352 online

http://www.jstage.jst.go.jp/browse/jos/ http://mc.manusriptcentral.com/jjocs
} 
the loss of appetite. In addition, the process of preparing nursing care food is likely to cause the loss of nutrition. During this process, a large quantity of water is used to soften food, such as in boiling and steaming. Minced food is often mixed with sauces made of water and thickener to minimize brittleness ${ }^{6)}$. As a result, the volume of a meal increases and its nutrition per unit weight decreases. It is easy for elderly people requiring nursing care to develop PEM together with a decrease of dietary intake. One report stated that elderly people consuming minced food have a poorer nutritional status than those with an ordinary diet $^{12)}$. Some studies on minced food at nursing care facilities showed that the energy content of such food was only $70 \%$ of the planned level and the actual energy intake of minced food was only $85 \%$ of that provided ${ }^{13,14)}$. Consequently, in elderly people consuming minced food, the risk of PEM is speculated to be high due to both nutritional loss during the preparation process and the decrease of food intake. Therefore, it is important to improve the ease of swallowing and the nutrition value of minced food in order to reduce PEM risk in the elderly requiring nursing care.

Oil and fat are efficient energy sources with a calorie level of $9 \mathrm{kcal} / \mathrm{g}$; they can produce a less harsh texture by their addition to food. Several nursing care food recipes using oil and fat have been shown to make foodstuffs smooth and easy to eat, but they just involved introduction in one case. Several studies reported that the addition of oil and fat improved the physical properties of food ${ }^{15,16)}$, but there have been no studies describing the differences of several kinds of oil and fat. In this study, for the purpose of improving the swallowing efficiency of minced food, we examined the different effects of oil and fat types on swallowing characteristics by rheology measurement and sensory evaluation. In addition, we newly developed gelatinous fat with the structure of an organogel. This gelatinous fat is aimed to form a soft bolus, and it has the characteris- tics of gathering together chopped and minced foodstuffs and not melting at body temperature in the mouth. We discussed the relationship between the kinds of oil and fat and the effects of improving swallowing.

\section{EXPERIMENTAL}

\subsection{Fat}

Commercially available oil and fat products with different physical states were employed in this study. Six types of oil and fat were used, including 3 simple types of fat in liquid, gelatinous, and solid states (referred to as liquid oil, gelatinous fat, and lard, respectively) and 3 emulsified types of fat (referred to as fresh cream[oil in water $\{\mathrm{o} / \mathrm{w}\}$ ], margarine [water in oil $\{\mathrm{w} / \mathrm{o}\}$ ], and butter[w/o]) (Table 1). The gelatinous fat was an organogel, which was modified by a technique to trap liquid oil within net-like structures that are composed of high-melting-point fat crystals. The gelatinous fat was composed of edible vegetable fat, edible refined fat, an emulsifier, and an antioxidant (vitamin $\mathrm{E}$ ). At $25^{\circ} \mathrm{C}$, the modified gelatinous fat had a firmness of 3,566 $\mathrm{N} / \mathrm{m}^{2}$, cohesiveness of 0.94 , and adhesiveness of $1,857 \mathrm{~J} / \mathrm{m}^{3}$ (measured according to the "Approval criteria for food products for people with difficulty in mastication and swallowing" for food products for special dietary uses in elderly people ${ }^{17)}$. Furthermore, the fatty-acid ratio of saturated fatty acids $(\mathrm{S})$ : monounsaturated fatty $\operatorname{acids}(\mathrm{M})$ : polyunsaturated fatty acids $(\mathrm{P})$ was 17:56:27, and that of n-3:n-6 was 1:2.

\subsection{Measurement of fat alone}

A dynamic viscoelastometer(RheoStress RS-1; HAAKE) was used to measure the temperature and frequency dependences of 6 fat materials. After the test materials had been placed onto a cone-shaped plate, the storage elastic

Table 1 Oils and fats used in this study.

\begin{tabular}{|c|c|c|c|c|c|}
\hline Type & \multicolumn{2}{|c|}{ Physical state } & \multirow{2}{*}{$\begin{array}{c}\text { Brand name } \\
\text { Matome Up } \\
\text { (Nisshin OilliO Co., Ltd.) }\end{array}$} & \multirow{2}{*}{$\begin{array}{c}\text { Source } \\
\text { Vegetable }\end{array}$} & \multirow{2}{*}{$\begin{array}{r}\text { Melting } \\
\text { point }\left({ }^{\circ} \mathrm{C}\right) \\
55\end{array}$} \\
\hline Gelatinous fat & Gel & Only oil & & & \\
\hline Liquid oil & Liquid & Only oil & $\begin{array}{c}\text { Nisshin Canola Oil } \\
\text { (Nisshin OilliO Co., Ltd.) }\end{array}$ & Vegetable & - \\
\hline Lard & Solid & Only oil & $\begin{array}{c}\text { Yukijirushi Lard } \\
\text { (Yukijirushi Food Co., Ltd.) }\end{array}$ & Animal & - \\
\hline Fresh cream & Emulsified $(\mathrm{o} / \mathrm{w})$ & With water & $\begin{array}{c}\text { Fresh Cream } \\
\text { (Yukijirushi Food Co., Ltd.) }\end{array}$ & Vegetable & - \\
\hline Margarine & Emulsified (w/o) & With water & $\begin{array}{c}\text { Neosoft } \\
\text { (Yukijirushi Food Co., Ltd.) }\end{array}$ & Vegetable & $30-32$ \\
\hline Butter & Emulsified (w/o) & With water & $\begin{array}{c}\text { Yukijirushi Butter } \\
\text { (Yukijirushi Food Co., Ltd.) }\end{array}$ & Animal & $28-38$ \\
\hline
\end{tabular}


$\operatorname{modulus}\left(G^{\prime}\right)$, the loss elastic modulus $\left(G^{\prime \prime}\right)$, and the mechanical loss tangent $\left(\tan \delta=G^{\prime \prime} / G^{\prime}\right)$ were measured at a shear rate of $6.28 \mathrm{rad} / \mathrm{s}, 1 \mathrm{~Hz}$ frequency, and $0^{\circ} \mathrm{C}-60^{\circ} \mathrm{C}$ to determine the temperature dependence. For frequency dependence, the same values were measured at shear rates of $0-6.28 \mathrm{rad} / \mathrm{s}, 37^{\circ} \mathrm{C}$, and $0.1-10 \mathrm{~Hz}$.

\subsection{Measurement of fat mixed with foodstuff}

\subsubsection{Preparation of test food}

The foodstuff used in this study was white chicken meat, which is prone to drying and becomes difficult for elderly people to eat. After the skin and gristle had been removed, $200 \mathrm{~g}$ of meat was combined with $15 \mathrm{~g}$ of alcohol and heated in a wrapped bowl in a microwave oven at $500 \mathrm{~W}$ for $4 \mathrm{~min}$. The meat was minced with fat that was equivalent to $20 \%$ of food volume $(\mathrm{w} / \mathrm{w})$ or minced without fat (control) using a food processor (DLC-10PRO, Cuisinart) for 1 min with occasional mixing with a spatula. The minced meat was placed in a stainless steel dish $(40 \mathrm{~mm}$ diameter, $15 \mathrm{~mm}$ height) and incubated at $5{ }^{\circ} \mathrm{C}, 25^{\circ} \mathrm{C}$, or $60^{\circ} \mathrm{C}$ for $2 \pm 1 \mathrm{~h}$.

2.3.2 Physical property assessment

A creep meter (RE-33005, YAMADEN Co., Ltd.) was used to assess the physical properties. In accordance with the test procedures described in the Approval criteria for food products for people with difficulty in mastication and swallowing, compression at a constant velocity was measured twice at a compression velocity of $10 \mathrm{~mm} / \mathrm{s}$ and clearance of $5 \mathrm{~mm}$ in an acrylic plunger $20 \mathrm{~mm}$ in diameter. Measurements were performed 3 times for each test food. We calculated firmness, adhesiveness, and cohesiveness on the basis of the obtained texture curves. The values obtained are expressed as means \pm standard deviations.

\subsubsection{Sensory assessment}

Sensory assessment was performed by 7 healthy volunteers $(39.5 \pm 6.9$ years old $)$ with neither olfaction/taste disorders nor dysphagia. The endpoints comprised 4 items regarding ease of swallowing (softness, smoothness, stickiness, and the feeling of residual food) and 2 items regarding taste (greasiness and palatability). The 6 materials were assessed and scored on a 5-point bipolar scale. At assessment, the following sensations were explained to the volunteers. Softness was assessed by the firmness experienced for test food mashed with the tongue, with scores from very hard, 1 , to very soft, 5 . Smoothness was assessed by the granularity of test food mashed with the tongue, with scores from very hard, 1 , to very smooth, 5 . Stickiness was assessed by the food sticking to the oral cavity during mastication, with scores of very strong, 1 , to very weak, 5 . The feeling of residual food was assessed by the residual food in the oral cavity and throat after swallowing, with scores from very strong, 1 , to very weak, 5 . Greasiness was expressed by the greasiness felt during mastication or after swallowing, with scores from very strong, 1 , very weak, 5 .
Palatability was assessed by the desirability of the food, with scores from very bad, 1 , to very good, 5 . There were 3 types of food: 2 containing fat(liquid oil or gelatinous fat) and 1 without fat. The types of fat were confirmed to have no specific flavor, and physical property assessment confirmed that they were minimally affected by temperature in terms of firmness. The test food was served at $25^{\circ} \mathrm{C}$. Room temperature ranged from $24^{\circ} \mathrm{C}$ to $26^{\circ} \mathrm{C}$. Assessments were performed according to a panel booth test. The subjects were allowed to consume the test food repeatedly. The use of a spoon was required. The amount of intake in 1 session was set as the optimal amount for each volunteer, who was allowed to consume the test food freely.

\subsection{Statistical analysis}

The results of the physical property assessment were analyzed with respect to each endpoint by 1-way analysis of variance. If there were significant differences between the test materials, multiple comparison analysis was performed with the Bonferroni/Dunn procedure. The sensory assessment results were statistically analyzed with respect to each endpoint using the Mann-Whitney U-test. Significance was set at $p<0.05$.

\section{RESULTS}

\subsection{Dynamic viscoelasticity}

Figure 1 illustrates the temperature dependence of the dynamic viscoelasticity of 6 fat types. Liquid oil (Fig. 1B) and fresh cream (Fig. 1D) were minimally affected by temperature changes and remained stable; $G^{\prime}$ and $G^{\prime \prime}$ of both of them were $<1 \times 10^{\circ} \mathrm{Pa}$, and $\tan \delta$ was $>1$. Lard (Fig. 1C), margarine (Fig. 1E), and butter (Fig. 1F), which are solid at room temperature, were greatly affected by temperature changes. They had high $G^{\prime}$ and $G^{\prime \prime}$ values of $1 \times$ $10^{4} \mathrm{~Pa}$ at $\leq 10^{\circ} \mathrm{C}, \leq 20^{\circ} \mathrm{C}$, and $\leq 30^{\circ} \mathrm{C}$. However, these values decreased rapidly as the temperature increased. Tan $\delta$ also changed markedly with respect to temperature. In contrast, both $G^{\prime}$ and $G^{\prime \prime}$ of the gelatinous fat (Fig. 1A) were stable at around $1 \times 10^{4} \mathrm{~Pa}$ from approximately $0^{\circ} \mathrm{C}$ to $50^{\circ} \mathrm{C}$. The $G^{\prime}$ of fat was always higher than the $G^{\prime \prime}$, and $\tan \delta$ was between 0.1 and 1 from $0{ }^{\circ} \mathrm{C}$ to $55^{\circ} \mathrm{C}$.

Figure 2 depicts the frequency dependence of dynamic viscoelasticity of the 6 fat types. Throughout the range of frequencies, the $G^{\prime}$ and $G^{\prime \prime}$ of gelatinous fat (Fig. 2A) were higher than those of the other types of fat. Despite an increased frequency, the $G^{\prime}$ of gelatinous fat remained essentially unchanged. Although the $G^{\prime \prime}$ decreased slightly, it generally remained constant at around $1 \times 10^{4} \mathrm{~Pa}$. Both $G^{\prime}$ and $G^{\prime \prime}$ of the other types of fat increased depending on the frequency. Although lard (Fig. 2C) had the second highest $G^{\prime}$ and $G^{\prime \prime}$ values following gelatinous fat, those of the other types of fat (Fig. 2B, 2D, 2E, 2F) were $\leq 1 \times 10^{\circ} \mathrm{Pa}$ 
Fig.1A: Gelatinous fat

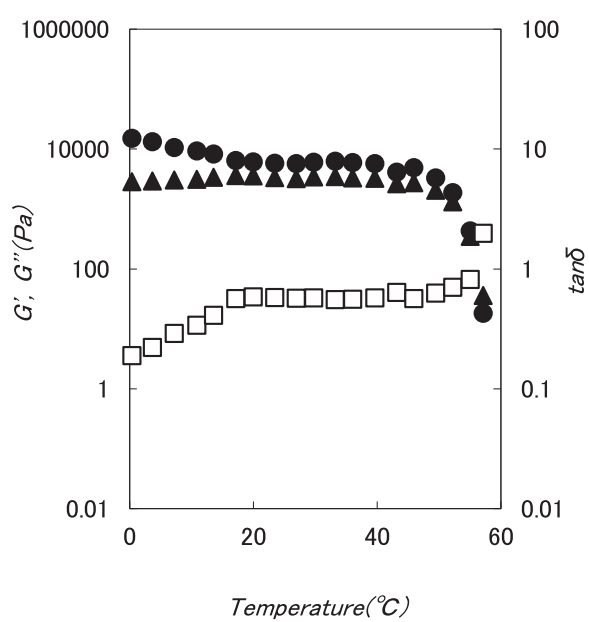

Fig.1C: Lard

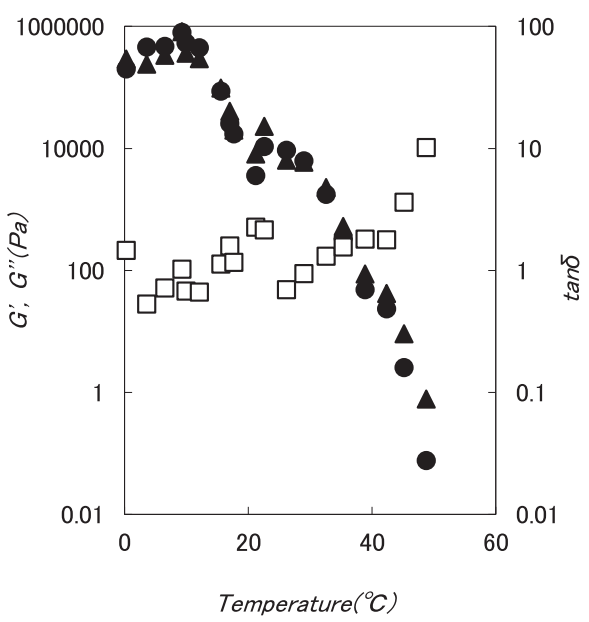

Fig.1E: Margarine

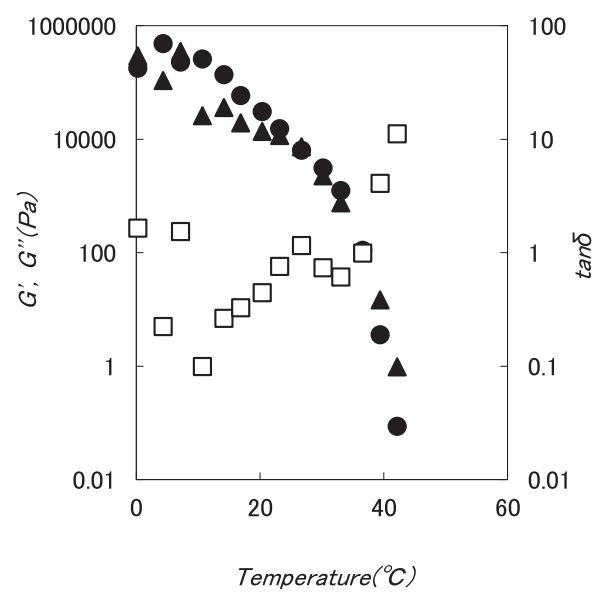

Fig.1B: Liquid oil

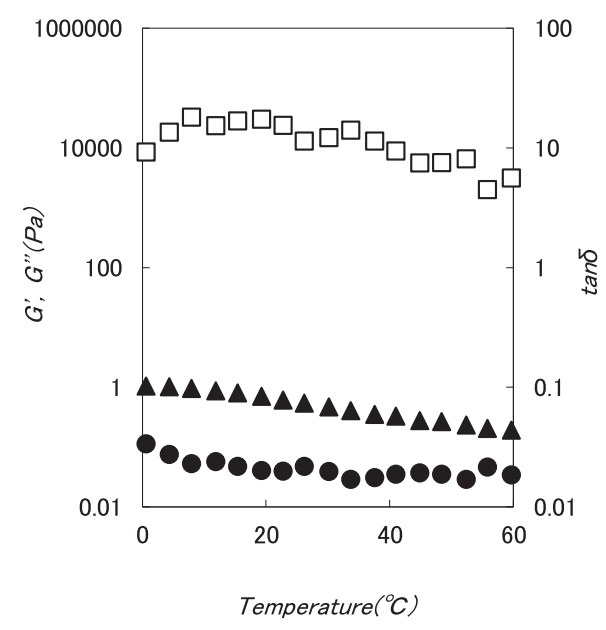

Fig.1D: Fresh Cream

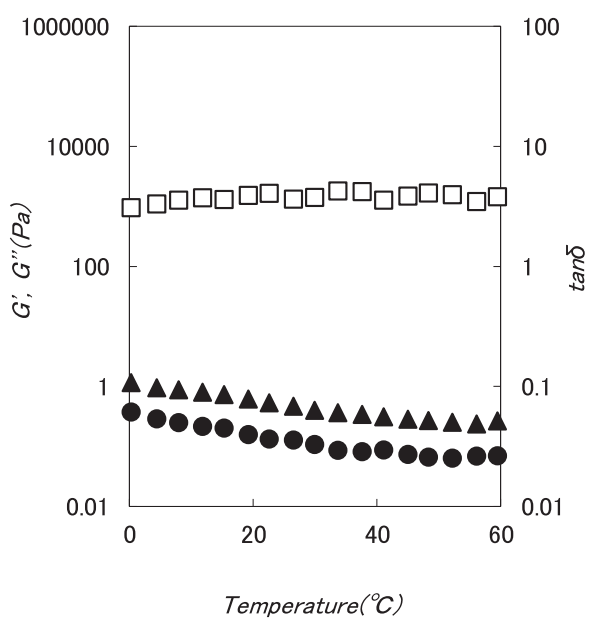

Fig.1F: Butter

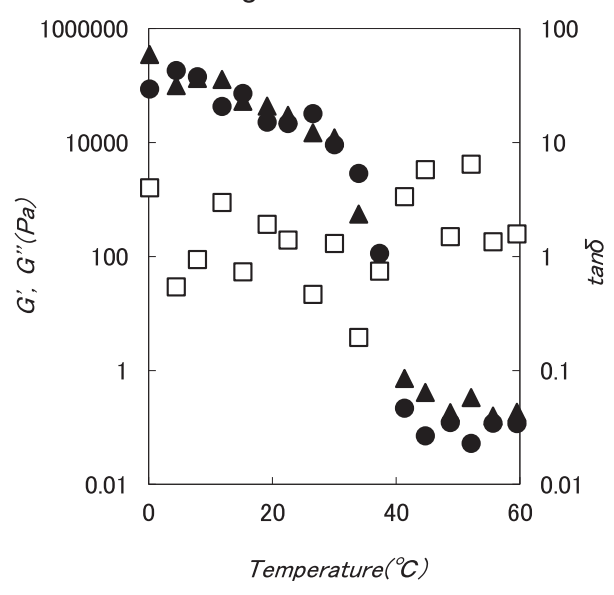

$$
: \mathrm{G}^{\prime} \quad \boldsymbol{\Delta}: \mathrm{G}^{\prime \prime} \quad \square: \tan \delta
$$

Fig. 1 Temperature dependence of dynamic viscoelasticity of 6 fat types. 
Fig.2A: Gelatinous fat

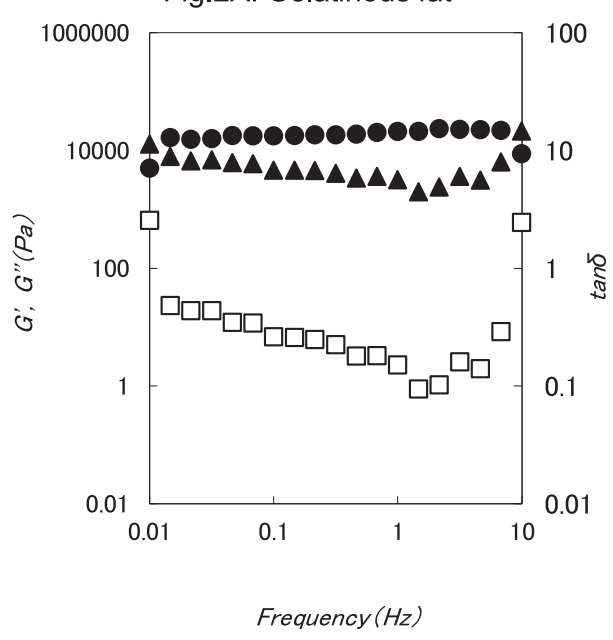

Fig.2C: Lard

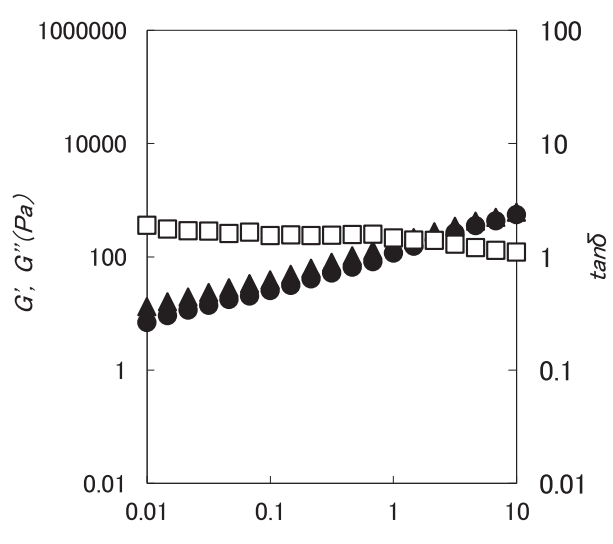

$\operatorname{Frequency}(\mathrm{Hz})$

Fig.2E: Margarine

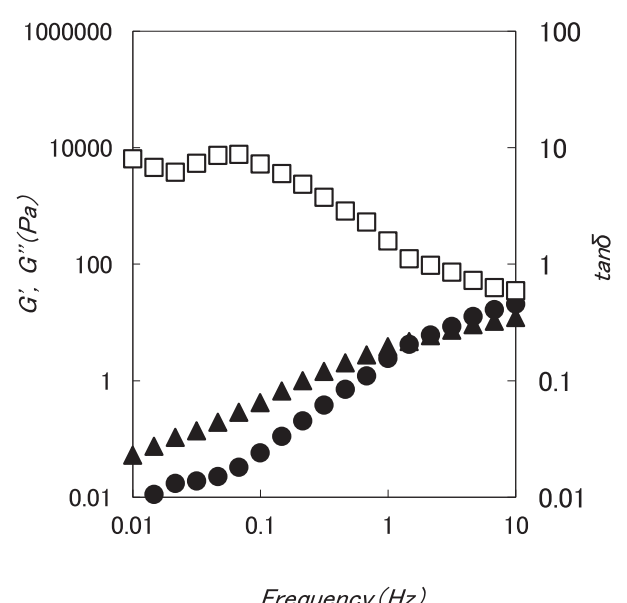

Fig.2B: liquid oil

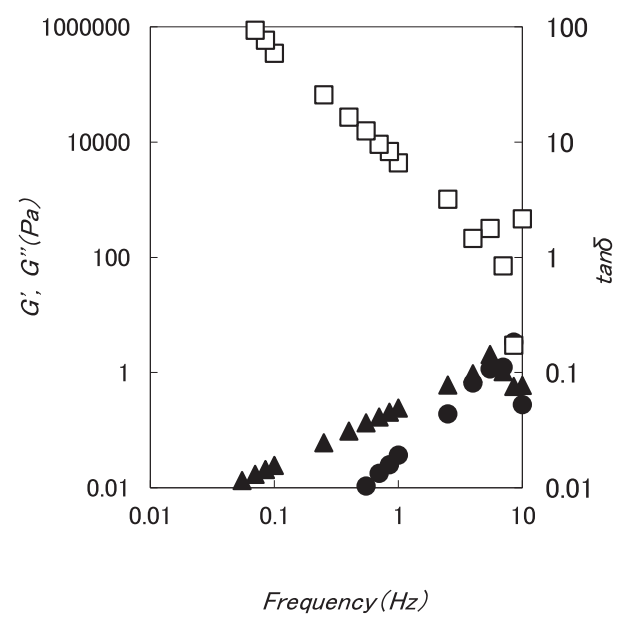

Fig.2D: Fresh cream

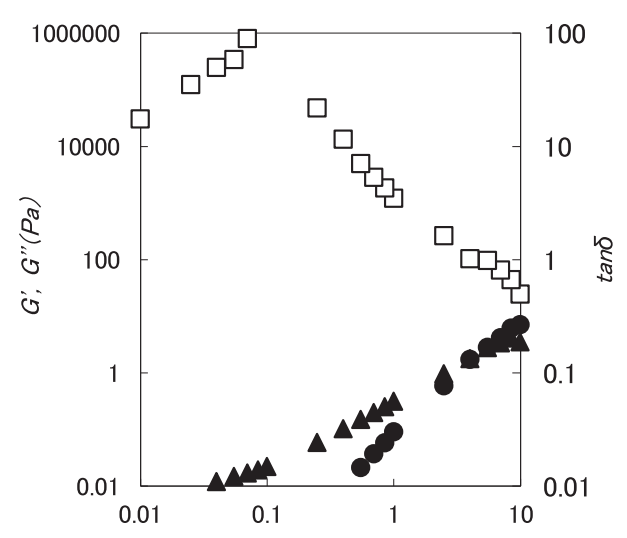

$\operatorname{Frequency}(\mathrm{Hz})$

Fig.2F: Butter

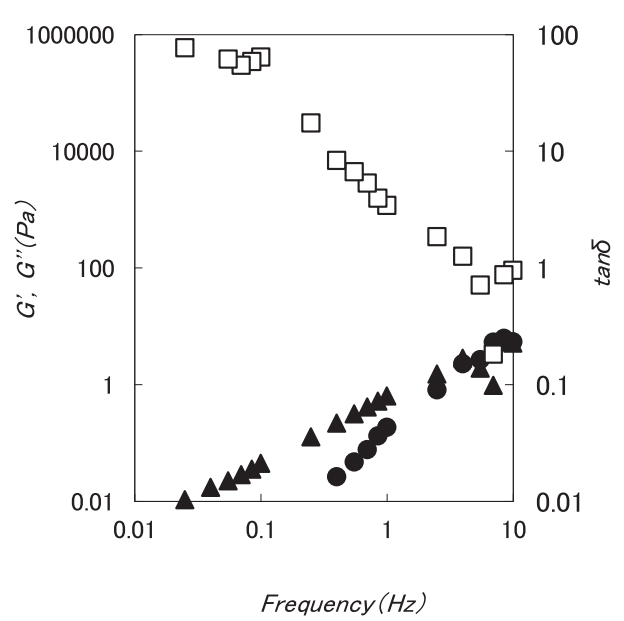

: $\mathrm{G}^{\prime} \quad \boldsymbol{\Delta}: \mathrm{G}^{\prime \prime} \quad \square: \tan \delta$

Fig. 2 Frequency dependence of dynamic viscoelasticity of 6 fat types. 
at nearly all frequencies. The gelatinous fat had constant $\tan \delta$ values between 0.1 and 1 , while the $\tan \delta$ of lard was approximately 1 . Other types of fat had $\tan \delta$ values $>1$ regardless of the frequency, and changed markedly in accordance with frequency.

\subsection{Rheological assessment}

Table 2 lists the results of rheological measurements when the different types of fat were added to the white chicken meat. Regarding firmness, the addition of fat softened the meat. Except for the test food containing butter at $5{ }^{\circ} \mathrm{C}$, the firmness values of all types of test food were significantly lower than those of the test food without fat. Comparisons among the types of fat revealed that the test food containing the gelatinous fat tended to be soft regard- less of the temperature. Compared with test food containing lard, fresh cream, and butter at $5{ }^{\circ} \mathrm{C}$, the addition of gelatinous fat at $25^{\circ} \mathrm{C}$ significantly softened the test food. The addition of liquid oil tended to soften the test food; only the gelatinous fat softened the test food more. The test food containing liquid oil was significantly softer than that containing lard, fresh cream, or butter at $5{ }^{\circ} \mathrm{C}$; moreover, the test food containing liquid oil was softer than that containing fresh cream or butter at $25^{\circ} \mathrm{C}$. Meanwhile, there were no significant differences among the types of fat with respect to softness at $60^{\circ} \mathrm{C}$. The variations in cohesiveness among the test materials were small. The comparison among temperatures revealed that cohesiveness was highest following the addition of gelatinous fat at $5{ }^{\circ} \mathrm{C}$ and $25^{\circ} \mathrm{C}$, whereas the test food without fat exhibited the

Table 2 The results of rheology evaluation.

(a) $5^{\circ} \mathrm{C}$

\begin{tabular}{ccccc}
\hline & & Firmness $\left(\mathrm{N} / \mathrm{m}^{2}\right)$ & Cohesiveness & Adhesiveness $\left(\mathrm{J} / \mathrm{m}^{3}\right)$ \\
\hline $\mathrm{a}$ & Without fat & $80432 \pm 10961^{\mathrm{a}}$ & $0.57 \pm 0.01^{\mathrm{b}}$ & $3996 \pm 937^{\mathrm{b}}$ \\
$\mathrm{b}$ & Gelatinous fat & $24452 \pm 531^{\mathrm{d}}$ & $0.68 \pm 0.02^{\mathrm{a}}$ & $5834 \pm 273^{\mathrm{b}}$ \\
$\mathrm{c}$ & Liquid oil & $32776 \pm 1592^{\mathrm{d}}$ & $0.56 \pm 0.02^{\mathrm{b}}$ & $5060 \pm 570^{\mathrm{b}}$ \\
$\mathrm{d}$ & Lard & $52026 \pm 3326^{\mathrm{bc}}$ & $0.57 \pm 0.06^{\mathrm{b}}$ & $7943 \pm 1276^{\mathrm{ab}}$ \\
$\mathrm{e}$ & Fresh cream & $49841 \pm 2409^{\mathrm{c}}$ & $0.61 \pm 0.01^{\mathrm{ab}}$ & $7402 \pm 313^{\mathrm{ab}}$ \\
$\mathrm{f}$ & Margarine & $37563 \pm 1735^{\mathrm{cd}}$ & $0.61 \pm 0.00^{\mathrm{ab}}$ & $7107 \pm 592^{\mathrm{ab}}$ \\
$\mathrm{g}$ & Butter & $65969 \pm 2819^{\mathrm{ab}}$ & $0.56 \pm 0.03^{\mathrm{b}}$ & $11193 \pm 809^{\mathrm{a}}$ \\
\hline
\end{tabular}

(b) $25^{\circ} \mathrm{C}$

\begin{tabular}{ccccc}
\hline & & Firmness $\left(\mathrm{N} / \mathrm{m}^{2}\right)$ & Cohesiveness & Adhesiveness $\left(\mathrm{J} / \mathrm{m}^{3}\right)$ \\
\hline a & Without fat & $76582 \pm 1283^{\mathrm{a}}$ & $0.57 \pm 0.01$ & $4456 \pm 657$ \\
$\mathrm{~b}$ & Gelatinous fat & $20706 \pm 294^{\mathrm{e}}$ & $0.64 \pm 0.06$ & $4542 \pm 538$ \\
$\mathrm{c}$ & Liquid oil & $27782 \pm 765^{\mathrm{d}}$ & $0.56 \pm 0.04$ & $3735 \pm 620$ \\
$\mathrm{~d}$ & Lard & $30487 \pm 819^{\mathrm{cd}}$ & $0.57 \pm 0.02$ & $4828 \pm 571$ \\
$\mathrm{e}$ & Fresh cream & $42765 \pm 1019^{\mathrm{b}}$ & $0.55 \pm 0.01$ & $4960 \pm 256$ \\
$\mathrm{f}$ & Margarine & $29447 \pm 147^{\mathrm{cd}}$ & $0.53 \pm 0.01$ & $4564 \pm 539$ \\
$\mathrm{~g}$ & Butter & $31736 \pm 1149^{\mathrm{c}}$ & $0.55 \pm 0.05$ & $4494 \pm 549$ \\
\hline
\end{tabular}

(c) $60^{\circ} \mathrm{C}$

\begin{tabular}{ccccc}
\hline & & Firmness $\left(\mathrm{N} / \mathrm{m}^{2}\right)$ & Cohesiveness & Adhesiveness $\left(\mathrm{J} / \mathrm{m}^{3}\right)$ \\
\hline $\mathrm{a}$ & Without fat & $58789 \pm 6888^{\mathrm{a}}$ & $0.61 \pm 0.00$ & $3603 \pm 500^{\mathrm{a}}$ \\
$\mathrm{b}$ & Gelatinous fat & $13631 \pm 389^{\mathrm{b}}$ & $0.56 \pm 0.02$ & $2121 \pm 76^{\mathrm{b}}$ \\
$\mathrm{c}$ & Liquid oil & $19666 \pm 1550^{\mathrm{b}}$ & $0.58 \pm 0.02$ & $2310 \pm 209^{\mathrm{b}}$ \\
$\mathrm{d}$ & Lard & $19458 \pm 147^{\mathrm{b}}$ & $0.58 \pm 0.01$ & $2307 \pm 398^{\mathrm{b}}$ \\
e & Fresh cream & $14151 \pm 641^{\mathrm{b}}$ & $0.59 \pm 0.01$ & $2388 \pm 266^{\mathrm{ab}}$ \\
$\mathrm{f}$ & Margarine & $17273 \pm 1283^{\mathrm{b}}$ & $0.57 \pm 0.03$ & $2636 \pm 337^{\mathrm{ab}}$ \\
$\mathrm{g}$ & Butter & $14671 \pm 883^{\mathrm{b}}$ & $0.59 \pm 0.03$ & $2524 \pm 446^{\mathrm{ab}}$ \\
\hline
\end{tabular}

Data are shown as means \pm standard deviations $(n=3)$.

Means with the same letter are not significantly different from each other $(p<0.05)$. 
highest value at $60^{\circ} \mathrm{C}$. Significant differences were only observed between the gelatinous fat and liquid oil, lard or butter at $5{ }^{\circ} \mathrm{C}$. There were no significant differences at $25^{\circ} \mathrm{C}$ or $60^{\circ} \mathrm{C}$. Adhesiveness tended to be lower with all types of fat as the temperature increased. At $5^{\circ} \mathrm{C}$, all types of fatcontaining test food had higher adhesiveness values than the test food without fat. The adhesiveness values of margarine, lard, and butter, which were solid at $5^{\circ} \mathrm{C}$, were high at $\geq 7,000 \mathrm{~J} / \mathrm{m}^{3}$. Although all types of test food containing fat tended to have high adhesiveness values at $25^{\circ} \mathrm{C}$, their adhesiveness was lower than that of the test food without fat at $60^{\circ} \mathrm{C}$ regardless of the type of fat used (except for liquid oil).

\subsection{Sensory assessment}

Figure 3 illustrates the sensory assessment results. Regarding the ease of swallowing (Softness, Smoothness, Stickiness, Feeling of residual food), favorable trends were observed among all items in the order of gelatinous fat (represented as B in Fig. 3), liquid oil(represented as A in Fig. 3), and test food without fat (represented as C in Fig. 3). Regarding softness, there was a significant difference between the test food containing gelatinous fat (B, $4.38 \pm$ $0.66)$ and the test food without fat $(\mathrm{C}, 2.63 \pm 0.66)$. There was no significant difference between the test food containing liquid oil $(\mathrm{A}, 3.63 \pm 0.81)$ and the test food without fat or between types of test food containing liquid oil or gelatinous fat. Regarding smoothness, significant differences were observed among all test materials (A, 3.63 \pm 0.66 ; B, $4.75 \pm 0.62 ; \mathrm{C}, 2.63 \pm 0.66)$. With respect to the feeling of residual food, there were significant differences between
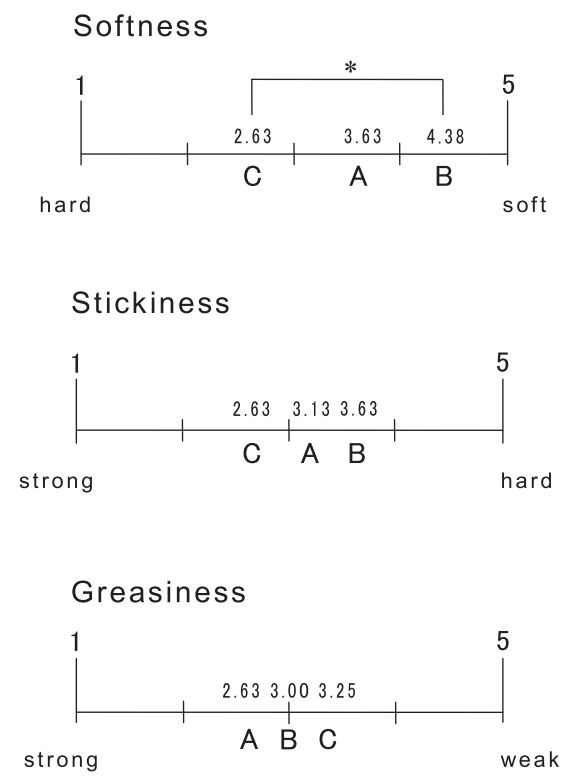

the test foods containing gelatinous fat $(\mathrm{B}, 4.25 \pm 0.78)$ and the test food containing liquid oil (A, 3.50 \pm 0.47$)$ and between the test foods containing gelatinous fat and the test food without fat $(C, 2.75 \pm 0.41)$. However, there was no significant difference between types of the test food containing liquid oil and the test food without fat. Regarding stickiness, there were no significant differences among any of the test materials (A, 3.13 \pm 0.57 ; B, 3.63 \pm 1.24 ; C, $2.63 \pm 0.66)$. With respect to taste, there were no significant differences in greasiness among any of the test mate-

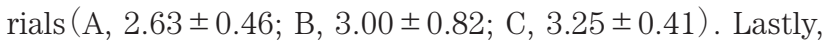
regarding palatability, significant differences in palatability were observed between the test food containing gelatinous fat (B, 4.13 \pm 0.74$)$ and the test food without fat (C, $3.00 \pm$ $0.67)$ and between the test food containing gelatinous fat and liquid oil $(\mathrm{A}, 3.13 \pm 0.57)$. Taking these findings together, the test food containing gelatinous fat was assessed as very palatable.

\section{DISCUSSION}

PEM is a serious problem for elderly people requiring nursing care. The problem of PEM was highlighted in Japan by Sugiyama's report, which showed the risk of PEM in elderly people to be about $40 \%$ at nursing care facilities and about $30 \%$ in home care ${ }^{18)}$. As a result, a system of nutrition care management utilizing screening and assessment was applied to them and the nutrition management was adapted for every case. However, it was also reported in subsequent research that about $60 \%$ of elderly people
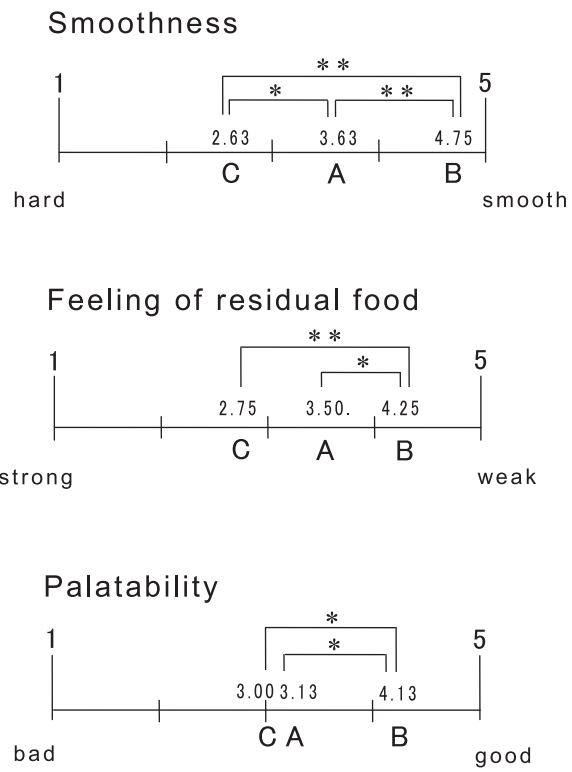

Fig. 3 Comparison of sensory assessment of test foods.

A: Food containing liquid oil B: Food containing gelatinous fat C: Food without fat Sensory assessment was performed by 7 healthy volunteers. Statistical analysis was done using the Mann-Whitney U-test $\left({ }^{*} p<0.05,{ }^{* *} p<0.01\right)$. 
with home care had or were likely to have $\mathrm{PEM}^{8)}$. No improvement of radical PEM was shown. One of the reasons for PEM is that the nutritional value of nursing care food can easily decrease. The texture that promotes swallowing is moderate softness, condensation as a bolus, and adequate stickiness $^{19)}$. However, most of the present types of nursing care food are adjusted for their texture by adding water and polysaccharide thickener. In addition, there are many types of soft food, such as cereals and vegetables, whereas it is difficult to cook meat and fish in a way that softens them, and their amounts used have tended to decrease. In fact, there are reports describing that the most difficult food to eat for the elderly in facilities is meat ${ }^{20)}$. Another report showed that numerous people at risk of malnutrition did not eat meat at all ${ }^{18)}$. These findings mean that the levels of protein and energy are likely to be decreased in terms of both the quantity offered and the actual intake. Recently, it was revealed that sarcopenia, involving a decrease of muscle, is emerging as a new problem for the elderly ${ }^{21)}$. From a preventive viewpoint, it would be important to increase the nutrition density of every meal and to increase protein and energy intake.

The gelatinous fat that we developed in this study has a structure of an organogel. Gel with water as the liquid component in the continuous phase is called hydrogel, while gel with liquid oil in the continuous phase is called organogel. Although hydrogels have been mainly used for nursing care food, organogels have better properties than hydrogels, such as weak polarity, resilience, and viscoelasticity $^{22,23)}$. Therefore, we considered that an organogel could be used as an aggregating ingredient of minced food, and developed an adjusted gelatinous fat in order to promote bolus formation.

In dynamic viscoelasticity measurement, the storage elastic modulus $\left(G^{\prime}\right)$ represents an elastic factor associated with firmness and structural maintenance and the loss elastic modulus $\left(G^{\prime \prime}\right)$ represents a viscous factor associated with vibrational absorption. The mechanical loss tangent, $\tan \delta$, is the ratio of $G^{\prime \prime}$ to $G^{\prime}$; if $\tan \delta$ exceeds 1 , the viscous factor exceeds the elastic factor. The main factors causing bolus disintegration are the force due to mastication and melting at body temperature. The mastication cycle in adults is 1-2 times/s, whereas that in elderly people is prolonged to compensate for decreased mastication force, being approximately 0.6 times $/ \mathrm{s}^{24,25)}$. On the basis of the range corresponding to the mastication cycle, both $G^{\prime}$ and $G^{\prime \prime}$ of gelatinous fat were extremely high and $\tan \delta$ was $<1$ in a frequency-dependence manner at 0.5-2 Hz. However, both $G^{\prime}$ and $G^{\prime \prime}$ of other types of fat were low and tan $\delta$ was $>1$. Regarding temperature dependence, the $G^{\prime}$ and $G^{\prime \prime}$ of liquid oil and fresh cream, which remain in a fluid state at all temperatures, were low. The $G^{\prime}$ and $G^{\prime \prime}$ of margarine, lard, and butter, which are solid types of fat, decreased when the temperature exceeded the melting point. On the other hand, the $G^{\prime}$ and $G^{\prime \prime}$ of gelatinous fat were stable at $1 \times 10^{4} \mathrm{~Pa}$ at $0{ }^{\circ} \mathrm{C}-55^{\circ} \mathrm{C}$. This is in accordance with the finding that gelatinous fat forms a strong crystal matrix with the structure of an organogel. Furthermore, the $G^{\prime}$ and $G^{\prime \prime}$ of gelatinous fat were highest at approximately body temperature. Referring to a report describing that a $\tan \delta$ value adequate for swallowing is between 0.1 and $1^{26)}$, only gelatinous fat had a $\tan \delta$ value between 0.1 and 1 at approximately body temperature. Likewise, only gelatinous fat had a $\tan \delta$ value between 0.1 and 1 in a frequency-dependent manner at 0.5-2 Hz. These results suggest that gelatinous fat is hard enough to be changed by the force and temperature associated with mastication, indicating that its physical properties inhibit bolus disintegration in the mouth.

Among various standards for the physical properties of nursing care food, one set of standards for people having difficulty masticating is Universal Design Foods (UDF), which is standardized into certain phases by firmness ${ }^{19,27)}$. When the present results are applied to the standards of UDF, food without fat corresponds to "category 1, easily chewable" and food with oil and fat corresponds to "category 2 , grindable with the gums". This means that the addition of oil and fat can produce food that is suitable for people with more serious difficulty masticating. The firmness should be $\leq 20,000 \mathrm{~N} / \mathrm{m}^{2}$ in "category 3 , grindable with the tongue," which is appropriate for people with more severe difficulties in mastication. In the measurement using a creep meter, only gelatinous fat satisfied the criteria for this category at $25^{\circ} \mathrm{C}$ and $60^{\circ} \mathrm{C}$. Moreover, only gelatinous fat could make meat softest and this property was not changed easily by temperature. This result is the same as that of the dynamic viscoelasticity result and it was confirmed that the physical properties of fat alone are related to those of fat mixed with food. In existing nursing care food adjusted with water and polysaccharide thickener, the change in physical properties by temperature is so serious that it causes many problems when eating ${ }^{28)}$. Since elderly people requiring nursing care need a longer time to eat, food that becomes harder and more difficult to eat as it cools is undesirable. On the other hand, white chicken meat adjusted with gelatinous fat showed little change in its physical properties with changing temperature. That is, it is clearly demonstrated that gelatinous fat might solve the problems regarding both the physical properties and the temperature change experienced with existing nursing care food.

In this study, the adhesiveness of white chicken meat did not decrease significantly even after the addition of fat. However, it has been shown that the hardness and adhesiveness of mashed potatoes supplemented with oil and fat were significantly lower than those supplemented with water, being different from our results ${ }^{17)}$. This difference is considered to be due to the effect of water existing in food; 
mashed potato includes water but white chicken meat does not. In this previous study concerning the ease of swallowing mashed potato, it was mentioned that this variable is related to the state of emulsification. Several studies have reported that the texture of food was improved considerably by emulsification of oil and fat supplementation, resulting in easy swallowing ${ }^{16,29,30)}$. In the sensory assessment of this study, both liquid oil and gelatinous fat significantly reduced the feeling of residual food, which is associated with adhesiveness, compared with food processed without fat. This result may be related to the occurrence of emulsification with oil and saliva during mastication. It is reported that there is a negative association between ease of swallowing and adhesiveness ${ }^{31)}$. In this study, water was not added to food, so the relationship between emulsification and adhesiveness upon a change in the amount of water added remains to be investigated.

In the case of white chicken meat used in this study, its minced food without any additional ingredients contains $0.98 \mathrm{kcal}$ of energy and $0.20 \mathrm{~g}$ of protein per g. In the case of preparation with a thickening agent, as water equivalent to $50 \%$ of food volume is added, the processed food contains $0.81 \mathrm{kcal}$ of energy and $0.13 \mathrm{~g}$ protein per $\mathrm{g}$ and the nutritional content decreases. On the other hand, in the case of the addition of fat equivalent to $20 \%$, the food contains $1.69 \mathrm{kcal}$ of energy and $0.19 \mathrm{~g}$ of protein per g, allowing the efficient intake of both energy and protein. Elderly people are likely to prefer softer foodstuffs due to tooth loss and decreased mastication force, resulting in energy, protein, and fat deficiencies ${ }^{32,33)}$. Thus, excessive intake of fat in elderly people may not be serious compared with that in the young. It has been reported that the administration of medium-chain triglycerides (MCT) to elderly people at high risk of malnutrition results in the improvement of serum albumin levels ${ }^{34)}$. Thus, in cases of PEM, it is important not only to increase protein intake but also to decrease protein catabolism by adjusting the energy content.

The addition of protease, salt, and acid can soften meat by dissolving myofibrillar proteins, but these processes have a disadvantage in that they are time-consuming. On the other hand, the process used in this study can soften meat without changing its form and this new technique is applicable to every kitchen. Food is routinely minced with gelatinous fat in food processors at nursing care facilities. For example, gelatinous fat is added to white fish and minced, or gelatinous fat is minced with raw meat and heated by steam convection, among others.

It was confirmed by rheology measurement and sensory evaluation that gelatinous fat is the type of fat that is most suitable for adjusting minced food. By using gelatinous fat, we can process a variety of types of nursing care food that have reduced nutritional losses and are less influenced by temperature change. It would be highly advantageous to apply new nursing care food processed with gelatinous fat rather than existing nursing care food processed with a large amount of water.

\section{CONCLUSION}

The purpose of this study was to improve the defects of existing nursing care food by using oil and fat; we investigated gelatinous fat, which is suitable for nursing care food. In the measurement of fat alone using a dynamic viscoelastometer, gelatinous fat had the highest values for the storage elastic modulus $\left(G^{\prime}\right)$ and the loss elastic modulus $\left(G^{\prime \prime}\right)$ at the predetermined ranges of temperature and frequency. The mechanical loss tangent $(\tan \delta)$ of gelatinous fat consistently ranged between 0.1 and 1 , indicating a weakly gelatinous physical property that facilitates swallowing. In the measurement of fat mixed with food using a creep meter, food with gelatinous fat had significantly lower firmness and exhibited a higher level of cohesiveness than that with other types of fat. In the sensory evaluation, food with gelatinous fat was better than food with no addition or the addition of liquid oil in terms of its softness, smoothness, low feeling of residual food, and palatability. These results indicate that gelatinous oil is the most suitable fat for nursing care food. It could be available to process many types of nursing care food with less energy loss and less change with varying temperature.

\section{References}

1) Hada, M.; Kanitani, Y.; Ichikawa, T.; Sato, S. The present condition and problems about dentistry related assessment items in the materials of the committee for certification of need for longterm care. Jpn. J. Gerodont. 16, 220-227 (2001).

2) Nagai, H.; Suzuki, T.; Shibata, H.; Matsumoto, N. The uses of Kizami (Minced Foods) Diets in special nursing homes for elderly. Jpn. J. Nutr. Diet. 52, 307-318 (1994).

3) Kojo, A.; Fuji, A.; Ynagisawa, Y.; Uematsu, H. Survey on the variety and application of meals provided in nursing and personal care facilities for the elderly. Jpn. J. Nutr. Diet. 62, 329-338(2004).

4) Nagai, H.; Suzuki, T.; Shibata, H. Relation between "Kizami(Minced Foods) Diet" and physical factors in a special nursing home for the elderly. Jpn. J. Nutr. Diet. 53, 369-376 (1995).

5) Oogoshi, H. Meals for People with Dysphagia - A study on the safety and texture of meals intended for the elderly - . J. Integr. Study Diet. Habits. 17, 288-296 (2007).

6) Yoshimura, M.; Kuwano, T.; Morisaki, R.; Nishihara, K. Rheological properties and sensory evaluation of the 
Minced Foods with xanthan Gum. J. Jpn. Soc. Mas. Sci. Health Pro. 14, 50-61 (2004).

7) Kuroda, R. "Geriatric Soft Food" appropriate to humans with dysphagia. Jpn. J. Dys. Rehab. 8, 10-16 (2004).

8) Izawa, S.; Kuzuya, M.; Okada, K.; Enoki, H.; Koike, T.; Kanda, S.; Iguchi, A. The nutritional status of frail elderly with care needs according to the mini-nutrtional Assessment. Clin. Nutr. 25, 962-967(2006).

9) Devoto, G.; Gallo, F.; Marchello1, C.; Racchi, O.; Garbarini, R.; Bonassi, S.; Albalustri, G.; Haupt, E. Prealbumin Serum Concentrations as a Useful Tool in the Assessment of Malnutrition in Hospitalized Patients. Clin. Chem. 52, 2281-2285(2006).

10) Fock, R. A.; Vinolo, M. A.; Crisma, A. R.; Nakajima, K.; Rogero, M. M.; Borelli, P. Protein-energy malnutrition modifies the production of interleukin-10 in response to lipopolysaccharide (LPS) in a murine model. J. Nutr. Sci. Vitaminol. 54, 371-377(2008).

11) Maruyama, T.; Kigawa, M.; Miura, A.; Shimizu, S. A trial of nutritional evaluation by mini nutritional assessment (MNA) at a welfare facility for the elderly. J. Jpn. Soc. Nuts. Food Sci. 59, 207-213 (2006).

12） Kikutani, T.; Kodama, M.; Nishiwaki, K.; Fukui, T.; Inaba, S.; Yoneyama, T. The relationship of oral, physical and mental functions to the nutritional status in the frail elderly. Jpn. J. Gerodont. 18, 10-16 (2003).

13) Yamashita, Y.; Akada, N. The effects of texture modification on the nutritional value of diets for the elderly. Bull. Hiroshima Bunka Gakuen Two-Year College 15-24 (2004).

14) Osuga, Y. A survey on the diet of elderly populationfoods - water-intake and excretion - . Bull. Toyama College 36, 105-113 (2001).

15) Watanabe, Y.; Ishihara, M.; Nakatsu, S.; Sakamoto, K. Vacuum oil infusion into frozen and thawed potato materials. J. Jpn. Soc. Food Sci. Technol. 58, 51-54 (2011).

16) Ishihara, M.; Watanabe, A.; Takahashi, T.; Fujii, K.; Ogoshi, H. Relationship between the hardness of mashed potato and its swallowing characteristics. $J$. Home Econ. Jpn. 51, 481-487 (2000).

17) Sano, J.; Yamagata, Y.; Kayashita, J. Investigation of test foods for videofluoroscopic examination of swallowing complying with criteria classifications of new foods for special dietary use system. Bull. Prefect. University of Hiroshima 6, 7-16 (2011).

18) Sugiyama, M.; Shimizu, R.; Wakaki, Y.; Nakamoto, N.; Koyama, W.; Mitsuhashi, H.; Koyama, M. Protein energy malnutrition in the elderly. Jpn. J. Nutr. Assess. 17, 553-562 (2000).

19) Sakai, M.; Kayashita, J. Physical properties of dysphagia patient. J. Jpn. Soc. Biorheol. 20, 10-19(2006).
20) Kojo, A.; Takagi, R. Food Preference of Elderly Patients in a Health Care Facility. Jpn. J. Nutr. Diet. 62, 153-160 (2004).

21) Wakabayashi, H. Sarcopenia and nutrition therapy nutritional status and quality of life in the elderly. $J$. Jpn. Soc. Parent. Enteral Nutr. 29, 837-842 (2014).

22) Sato, K. Fat crystallization processes in bulk and dispersed states. Oleoscience 5, 3-11(2005).

23) Higaki, K.; Sasakura, Y.; Koyano, T.; Hachiya, I.; Sato, K. Physical analyses of gel-like behavior of binary mixtures of high- and low-melting fats. J. Am. Oil Chem. Soc. 80, 263-270 (2003).

24) Takahashi, J.; Nakazawa, F. Evaluation of food texture by masticatory pattern. J. Home Econ. Jpn. 38, 107$113(1987)$.

25) Ooyama, T.; Akutsu, S.; Ito, K.; Watanabe, T.; Kohyama, K. Electromyography study of mastication of pickles by young and elderly people. J. Jpn. Soc. Food Sci. Technol. 56, 14-19(2009).

26) Funami, T. Rheological measurements of food products. J. Jpn. Soc. Biorheol. 21, 16-26 (2007).

27) Fujisaki, T. Universal Design Foods. J. Jpn. Soc. Food Sci. Technol. 55, 78-79(2008).

28) Sakai, M.; Kayashita, J. Effects of temperature on physical properties of foods for dysphagia. Bull. Prefect. University of Hiroshima 2, 49-62 (2001).

29) Yagi, J.; Ishihara, A. Examination in correlation between dynamic viscoelasticity and sensory test on foods. Rep. Shizuoka Prefect. Ind. Technol. Cent. 45, 109-112 (2010).

30) Takeyama, S.; Nishida, S.; Ono, A.; Toyama, R. Development of boiled fish products as a preventive foods of nursing care. Rep. Iwate Prefect. Ind. Technol. Cent. 14, 28-31 (2008).

31) Takahashi, T.; Sonoda, A.; Kouda, E.; Nakamura, S.; Ogoshi, H. Physical properties of gel-type food, and how the intake quantity per mouthful affects the masticating method and frequency of swallowing. Jpn. J. Nutr. Diet. 66, 231-240 (2008).

32) Nagai, H.; Shibata, H.; Houga, H.; Ueno, M.; Suyama, Y.; Yasuhara, S.; Matuzaki, T.; Sakihara, M.; Taira, K. The relationship of chewing ability to nutrient and food intakes in the community elderly. Jpn. J. Public Health 38, 853-858(1991).

33) Yamauchi, T.; Koide, A. The relationship between masticatory ability and dietary intake in elderly. Bull. $\mathrm{Na}$ goya Women's University 54, 89-98 (2008).

34) Nosaka, N.; Adachi, K.; Kawashima, Y.; Suzuki, H.; Hayashi, H.; Aoyama, T.; Nakamura, T. Effect of ingestion of medium-chain fatty acids on serum albumin in the elderly with protein-energy malnutrition (PEM). $J$. Jpn. Soc. Clin. Nutr. 32, 52-61(2010). 